Article

\title{
Long-Term Occurrence of Deoxynivalenol in Feed and Feed Raw Materials with a Special Focus on South Korea
}

\author{
Juhee Park $^{1}$, Hansub Chang ${ }^{2}$, Dongho Kim ${ }^{2,3}$, Soohyun Chung ${ }^{3}$ and Chan Lee ${ }^{1, *(D)}$ \\ 1 Advanced Food Safety Research Group, BrainKorea21 Plus, Department of Food Science and Technology, \\ Chung-Ang University, 4726, Seodong-daero, Anseong-si 17546, Gyeonggi-do, Korea; bjhwngml@naver.com \\ 2 National Agricultural Products Quality Management Service, 141, Yongjeon-ro, Gimcheon-si 39660, \\ Gyeongsangbuk-do, Korea; jjhs@korea.kr (H.C.); anoldmu@korea.kr (D.K.) \\ 3 Department of Integrated Biomedical and Life Science, Korea University, Seoul 02841, Korea; \\ chungs59@korea.ac.kr \\ * Correspondence: chanlee@cau.ac.kr; Tel.: +82-670-3035; Fax: +82-676-8865
}

Received: 5 February 2018; Accepted: 15 March 2018; Published: 16 March 2018

\begin{abstract}
The Fusarium fungi produce toxic substances called mycotoxins, which can cause disease and harmful effects in grains, livestock, and humans. Deoxynivalenol (DON), also known as vomitoxin, is one of the Fusarium mycotoxins that is known to cause vomiting in livestock. This study shows the occurrence of deoxynivalenol in feedstuffs (compound feed and feed ingredients) between 2009 and 2016 in South Korea. A total of 653 domestic samples were collected at five time points, including 494 compound feed samples and 159 feed ingredient samples. DON contamination levels were analyzed using high-performance liquid chromatography (HPLC) with pretreatment using an immunoaffinity column (IAC). The limit of detection (LOD) and the limit of quantification (LOQ) were estimated at 1-10 $\mu \mathrm{g} / \mathrm{kg}$ and 3-35 $\mu \mathrm{g} / \mathrm{kg}$, respectively. Two compound feeds (two gestating sow feed samples) out of 160 pig feed samples exceeded the European Commission (EC) guidance value, while no feed ingredient samples exceeded the EC or South Korean guidance values. There were statistically significant differences in the mean contamination levels of compound feed and feed ingredients that indicated a decreasing trend over time.
\end{abstract}

Keywords: mycotoxin; deoxynivalenol; animal feed; compound feed; feed ingredient

Key Contribution: The occurrence of deoxynivalenol produced by Fusarium fungi was studied between 2009 and 2016 in South Korea.

\section{Introduction}

Mycotoxins produced from Fusarium species are a serious problem for grains and maize, and many researchers have reported that Fusarium toxins may affect livestock and humans in various countries [1,2]. Fusarium toxins have traditionally been associated with the temperature at which the cultivation, harvest, and storage of cereals occur. These fungi are mesophilic with an optimum temperature for growth and mycotoxin production between 20 and $30^{\circ} \mathrm{C}$. Therefore, many reports have demonstrated the global scale of grain contamination with a number of Fusarium toxins including fumonisins (FUMs), zearalenone (ZEN), and deoxynivalenol (DON) to name a few [3-5].

Trichothecenes are mycotoxins produced by various Fusarium genera that are classified into A, B, C, and D type groups according to their chemical properties. DON belongs to type B [6], which has a double bond with oxygen at the number 8 carbon in the molecular structure [7]. The chemical structure of DON is shown in Figure 1. 


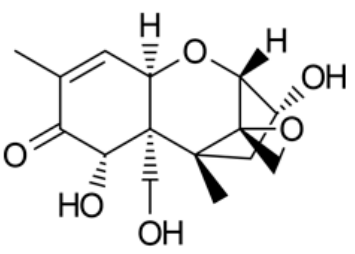

Figure 1. Chemical structure of deoxynivalenol (DON).

DON was discovered by Morooka et al. in 1972 as produced by Fusarium graminearum on cereals such as wheat, maize, and barley [8]. DON is a colorless bed-type crystal granule, and has heat stability at $120{ }^{\circ} \mathrm{C}$. DON is soluble in water and some organic solvents [9]. Protein synthesis is inhibited by this mycotoxin through interference with peptidyl transferase activity combined with intracellular ribosomes [10]. DON induces impaired growth and weight gain in animals [11]. In addition, DON causes typical intoxication of livestock and also induces vomiting, leading to a decrease in feed intake and feeding refusal symptoms at high concentrations. In a chronic toxicity test at low concentrations, DON did not induce any changes related to animal behavior; biochemical, hematological, or biochemical characteristics; or immunological parameters [12]. Swine was highly sensitive to DON. This toxin is classified as a group 3 carcinogen by the International Agency for Research on Cancer (IARC) [9].

The occurrence of DON in food and animal feed is a significant problem for the livestock industry and for the supply chain and international trade in food and feed [1,13]. Rodrigues and Naehrer [14] reported a three-year survey related to the presence of mycotoxins in feedstuffs and feed worldwide. Aflatoxins (AFs), ZEN, DON, FUMs, and ochratoxin A (OTA) were detected in 33, 45, 59, 64, and $28 \%$ of all analyzed samples including soybean meal, wheat, corn, finished feed samples, and dried distillers grains with solubles (DDGS) from the Americas, Europe, and Asia. DON showed the second highest occurrence.

In China, a total of 56 wheat samples were analyzed for DON contamination levels [15]. Among them, $89.3 \%$ of cereal samples were contaminated with DON in the range of 259 to $4975 \mu \mathrm{g} / \mathrm{kg}$. In a study in Tunisia, durum wheat samples (65) were contaminated with DON [16] that ranged from $12.8 \pm 5 \%$ to $30.5 \pm 13.3 \% \mu \mathrm{g} / \mathrm{g}$. Pietsch et al. [17] reported that $81.8 \%$ of commercial fish feed samples (11) collected from central Europe were contaminated with DON. The average contamination value was $289 \mu \mathrm{g} / \mathrm{kg}$ feed. In South Korea, DON was detected in $91.3 \%$ and $53.3 \%$ of compound feeds and feed ingredients, respectively [18].

The European Commission (EC) provided recommended guidance values for mycotoxins in animal feed for aflatoxin (AF), ochratoxin (OCT), and other Fusarium mycotoxins. The USA has also managed aflatoxin, DON, and fumonisins (FUM) in feeds [19]. In South Korea, the guidance level for AF and OCT in animal feed has been managed according to the guidelines for livestock and fish feed up to 2014. However, recently, levels of Fusarium mycotoxins in feed have been controlled based on continuous monitoring results and the EC's recommended guidance values. The values for DON management in the EU [19] and South Korea [20] are shown in Table 1.

Animal feedstuffs are composed of grains and grain byproducts with vegetable proteins. In 2012, 15,350 tons of feed ingredients were imported by South Korea from many countries such as China, USA, Europe, Canada, South Africa, South East Asia, Australia, and India [21]. This indicates that not only animal feedstuffs but also feed ingredients including grain, grain by-products, and meal should be controlled for feed safety. Therefore, this study was performed to monitor DON contamination levels in feed ingredients, as well as in animal feedstuffs, over an eight-year period to estimate the tendency of DON contamination. 
Table 1. Recommended guidance values for DON in animal feed in the EU and South Korea.

\begin{tabular}{|c|c|c|c|}
\hline \multirow[t]{2}{*}{ Mycotoxin } & \multirow{2}{*}{ Products Intended for Animal Feed } & \multicolumn{2}{|c|}{$\begin{array}{l}\text { Guidance Value } \\
\text { in } \mathrm{mg} / \mathrm{kg}(\mathrm{ppm})\end{array}$} \\
\hline & & EU & Korea \\
\hline \multirow{8}{*}{ Deoxynivalenol } & Feed material & & \\
\hline & - Cereals and cereal products with the exception of maize by-products & 8 & 10 \\
\hline & - Maize by-products & 12 & - \\
\hline & Complementary and complete feed stuffs with the exception of maize by-products & 5 & - \\
\hline & - Complementary and complete feed stuffs for pigs & 0.9 & 0.9 \\
\hline & - Complementary and complete feed stuffs for calves ( $<4$ months), lambs, and kids & 2 & - \\
\hline & - Complementary and complete feed stuffs for ruminants & - & 2 \\
\hline & - Other complementary and complete feed stuffs & - & 5 \\
\hline
\end{tabular}

\section{Results}

\subsection{Method Validation}

A clear peak for DON was observed on the HPLC (high-performance liquid chromatography) chromatogram by pretreatment using an immunoaffinity column (IAC) (Figure 2A). The regression coefficient was calculated to be over 0.999 based on the standard curve (solvent-based) for DON (Figure 2B). The limit of detection (LOD) was 1 to $10 \mu \mathrm{g} / \mathrm{kg}$ and the limit of quantification (LOQ) was 3 to $35 \mu \mathrm{g} / \mathrm{kg}$ for tested years. Accuracy was calculated from the average recovery ratio obtained from the recovery test, and precision was the percent relative standard deviation (\%RSD) calculated from the same tests. The accuracy range was $83.3 \%$ to $108.3 \%$, and the RSD was $1.4 \%$ to $13.9 \%$ (Table 2). These results meet the EC-recommended guidance value for DON during all test years, meaning that accuracy was $70 \%$ to $120 \%$ and precision was under $20 \%$ [22].

Further identification of DON was performed using LC-MS/MS with the extracted ion chromatogram (XIC) and mass spectrum (Figure 3). The XIC for DON in standard solution and in contaminated samples (Figure 3A,B) showed the same precursor ion with $m / z$ of $355.1\left([\mathrm{M}-\mathrm{H}]^{-}\right.$). The XIC for DON showed the two product ions of $m / z 58.9$ and 295.2 as shown in Figure 3C, and the two product ions from XIC for the feed sample were exactly matched with those of DON in the standard solution (Figure 3D).

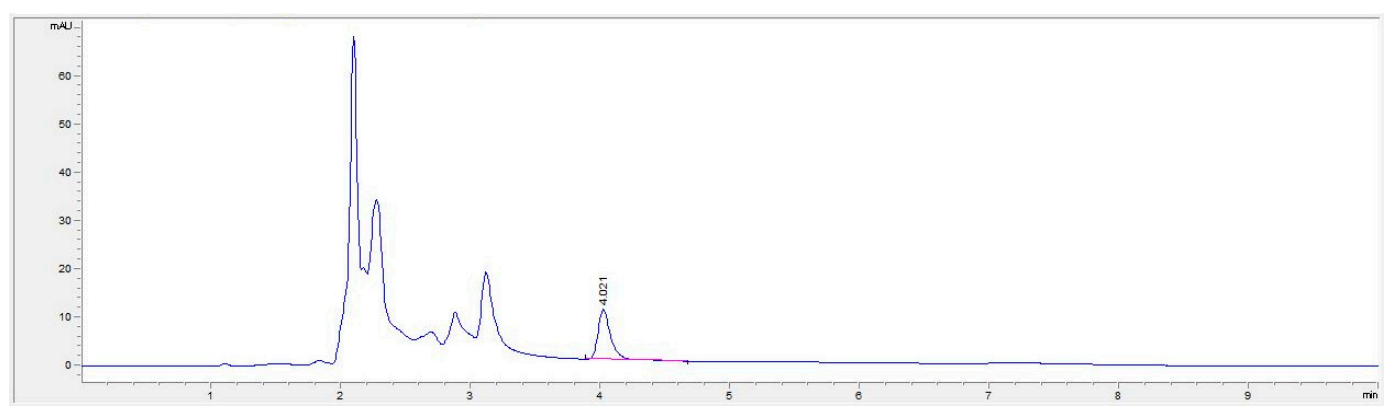

(A)

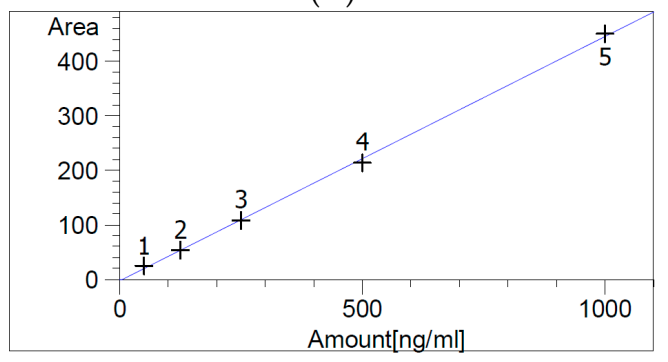

(B)

Figure 2. Calibration curve for DON (A) and the HPLC chromatogram (B). 


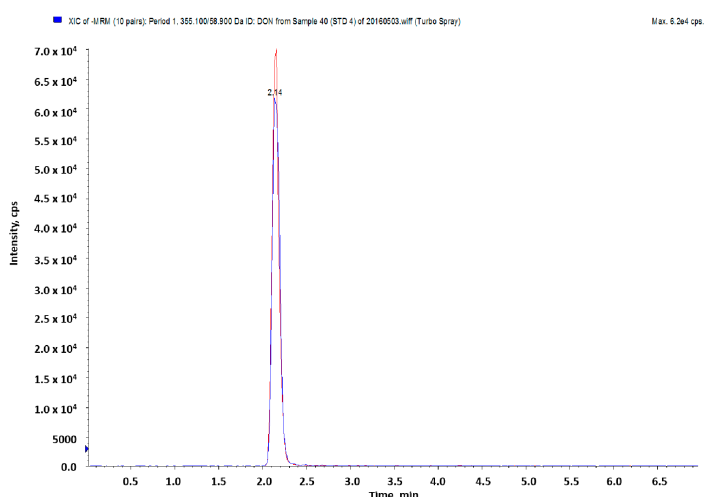

(A)

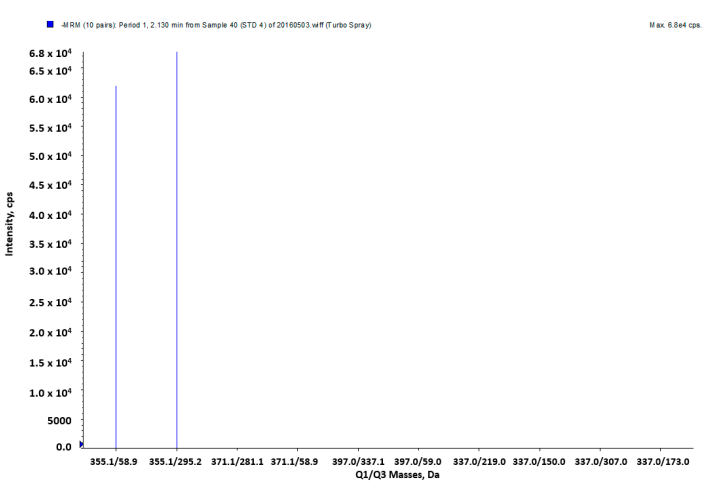

(C)

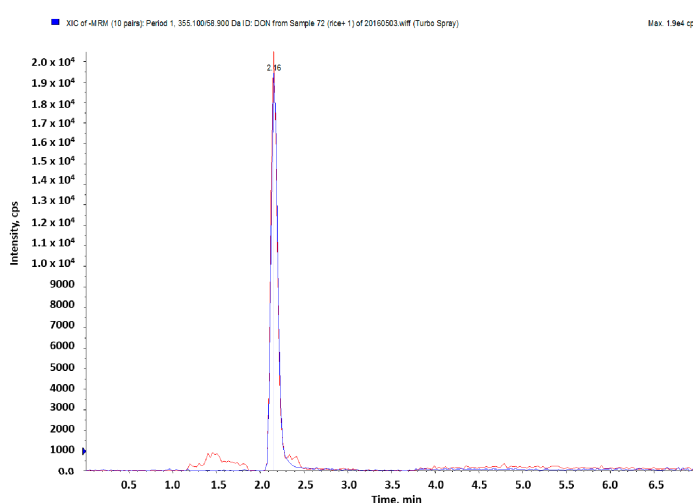

(B)

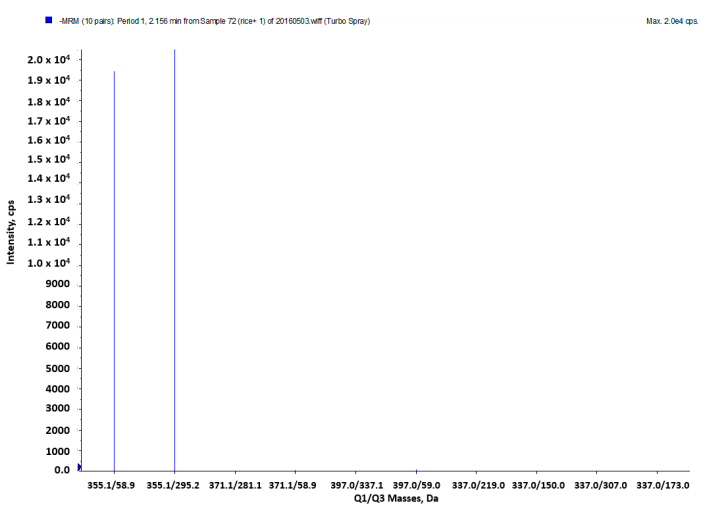

(D)

Figure 3. Identification of DON by LC-MS/MS. An extracted ion chromatogram (XIC) of the DON standard at $510 \mathrm{ppb}(\mathbf{A})$ and DON in a feed sample (B). The ion spectrum (product ion) of standard DON $(\mathbf{C})$ and those in a feed sample (D).

Table 2. Summary of the method validation study.

\begin{tabular}{|c|c|c|c|c|c|c|}
\hline \multirow{2}{*}{$R^{2}$} & \multirow{2}{*}{$\begin{array}{c}\text { LOD } \\
(\mu \mathrm{g} / \mathrm{kg})\end{array}$} & \multirow{2}{*}{$\begin{array}{c}\text { LOQ } \\
(\mu \mathrm{g} / \mathrm{kg})\end{array}$} & \multicolumn{4}{|c|}{ Recovery } \\
\hline & & & Spiked Concentrations ( $\mu \mathrm{g} / \mathrm{kg})$ & Mean Recovery (\%) & SD & RSD (\%) \\
\hline \multirow{6}{*}{0.999} & \multirow{6}{*}{$1-10$} & \multirow{6}{*}{$3-35$} & 50 & 95.6 & 13.3 & 13.9 \\
\hline & & & 100 & 107.7 & 3.9 & 3.7 \\
\hline & & & 200 & 95.4 & 7.7 & 4.0 \\
\hline & & & 250 & 83.3 & 6.1 & 7.3 \\
\hline & & & 500 & 108.3 & 4.3 & 3.9 \\
\hline & & & 1000 & 88.8 & 12.4 & 1.4 \\
\hline
\end{tabular}

$R^{2}$, regression coefficient; LOD, limit of detection; LOQ, limit of quantitation; SD, standard deviation; RSD, relative standard deviation.

\subsection{Occurrence of DON in Compound Feeds between 2009 and 2016}

The DON contamination level was assessed in 174 cattle feed, 160 pig feed, and 160 poultry feed samples (Table 3). Samples were collected in 2009, and in every subsequent two years from 2010 to 2016 (2010, 2012, 2014 and 2016). Most samples (97.7\% of cattle feed, 93.1\% of pig feed, and 95.0\% of poultry feed samples) were contaminated with DON; DON was found in $95.3 \%$ of the samples. To describe how were samples with DON level < LOD managed for statistical analysis, statistical definition (Percentage of Left censored results; \% LC) was applied to exhibit a data point in statistics below a certain value but it is unknown by how much. \% LC was generally used in safety assessment as described by EFSA [23], and we applied this statistics term to explain the percentage of data below LOD which exhibit where the observed data is located in percentage. The mean concentration of 
DON contamination in all feeds was $374.5 \mu \mathrm{g} / \mathrm{kg}$ in the range of 0.4 to $2420.0 \mu \mathrm{g} / \mathrm{kg}$. The mean contamination level of DON in cattle feed, pig feed, and poultry feed samples was 646.3, 231.5, and $222.0 \mu \mathrm{g} / \mathrm{kg}$, respectively. The highest level of DON contamination was observed in cattle feed samples among the three types of compound feed samples after statistical comparison. In a one-way analysis of variance (ANOVA), there was a significant difference among the three groups of compound feed samples $(p<0.001)$. Scheffe's method was used to determine the average contamination difference in DON (Table 4).

Table 3. DON levels in various compound types.

\begin{tabular}{|c|c|c|c|c|c|}
\hline Livestock & Feed Type & $N^{(\mathrm{a})}$ & LC (\%) (b) & Mean $(\mu \mathrm{g} / \mathrm{kg})$ & $\mathrm{SD}(\mu \mathrm{g} / \mathrm{kg})$ \\
\hline \multirow{5}{*}{ Beef cattle } & Early beef cattle & 21 & 0 & 646.9 & 452.6 \\
\hline & Middle beef cattle & 8 & 12.5 & 709.2 & 473.3 \\
\hline & Late beef cattle & 20 & 5 & 738.2 & 486.0 \\
\hline & Gestating beef cattle & 29 & 0 & 831.2 & 521.3 \\
\hline & Lactating beef cattle & 2 & 0 & 887.5 & 707.5 \\
\hline \multirow{5}{*}{ Dairy cows } & Dairy cows in early lactation & 16 & 0 & 505.2 & 350.3 \\
\hline & Dairy cows in mid lactation & 5 & 0 & 801.4 & 296.7 \\
\hline & Dairy cows on dry & 4 & 0 & 605.1 & 158.5 \\
\hline & High yielding dairy cows & 9 & 0 & 601.8 & 375.6 \\
\hline & Gestating dairy cows & 5 & 0 & 585.5 & 336.5 \\
\hline \multirow{7}{*}{ Calves } & Early beef calves & 9 & 11.1 & 580.3 & 256.0 \\
\hline & Middle beef calves & 11 & 9.1 & 420.6 & 252.8 \\
\hline & Early dairy calves & 1 & 0 & 125.0 & 0.0 \\
\hline & Middle dairy calves & 15 & 0 & 600.6 & 387.4 \\
\hline & Late dairy calves & 13 & 0 & 700.6 & 552.1 \\
\hline & Middle breeding calves & 1 & 0 & 28.1 & 0.0 \\
\hline & Late breeding calves & 5 & 0 & 315.0 & 213.3 \\
\hline \multirow{2}{*}{ Pigs } & Early growing pigs & 30 & 3.3 & 201.8 & 174.3 \\
\hline & Late growing pigs & 18 & 0 & 217.6 & 167.8 \\
\hline \multirow{3}{*}{ Sows } & Gestating sows & 32 & 3.1 & 392.1 & 338.8 \\
\hline & Lactating sows & 25 & 12 & 225.7 & 221.0 \\
\hline & Breeding gilts & 1 & 0 & 162.8 & 0.0 \\
\hline \multirow{2}{*}{ Piglets } & Sucking piglets & 8 & 12.5 & 55.1 & 38.8 \\
\hline & Weanling piglets & 46 & 10.9 & 179.7 & 164.5 \\
\hline \multirow{10}{*}{ Poultry } & Early layer chicks & 9 & 0 & 238.3 & 164.8 \\
\hline & Middle layer chicks & 22 & 0 & 285.6 & 254.4 \\
\hline & Late layer chicks & 8 & 0 & 406.2 & 377.3 \\
\hline & Early laying hens & 27 & 7.4 & 314.7 & 258.7 \\
\hline & Middle laying hens & 11 & 9.1 & 251.0 & 217.0 \\
\hline & Late laying hens & 2 & 50 & 72.5 & 72.5 \\
\hline & Early broilers & 37 & 2.7 & 148.6 & 135.5 \\
\hline & Late broilers & 33 & 3.0 & 162.5 & 89.7 \\
\hline & Finishing broilers & 2 & 0 & 152.8 & 34.8 \\
\hline & Breeding broilers & 9 & 22.2 & 140.4 & 177.1 \\
\hline
\end{tabular}

Table 4. DON concentration mean and differences in compound feeds.

\begin{tabular}{lcccccc}
\hline \multirow{2}{*}{ Mycotoxins } & Livestock & \multicolumn{2}{c}{ Conc. of Mycotoxin $(\mu \mathrm{g} / \mathbf{k g})$} & \multirow{2}{*}{$\boldsymbol{F}$} & \multirow{2}{*}{$\boldsymbol{p}$} \\
\cline { 3 - 4 } & & Mean & SD & & \\
\hline \multirow{3}{*}{ Deoxynivalenol } & Cattle & $646.28^{\mathrm{b}}$ & 452.58 & & \\
& Pig & $231.47^{\mathrm{a}}$ & 235.30 & & $94.363^{* * *}$ & 0.000 \\
& Poultry & $221.93^{\mathrm{a}}$ & 215.81 & & \\
\hline
\end{tabular}

\footnotetext{
${ }^{\mathrm{b}}>^{\mathrm{a}}=$ significant mean difference by Scheffe tests; ${ }^{* * *} p<0.001 ; F, F$-value.
} 
According to the EC, DON guidance level in feed for calves ( $<4$ months), lambs, and kids is $2000 \mu \mathrm{g} / \mathrm{kg}$ and the guidance level for feed for pigs is $5000 \mu \mathrm{g} / \mathrm{kg}$. In our study, no sample exceeded the EC guidance values for cattle and poultry feed. However, two compound feed samples (two gestating sow feed samples) out of 160 pig feed samples showed DON contamination in excess of the EC guidance value of $900 \mu \mathrm{g} / \mathrm{kg}$. The distribution of DON according to type of livestock is shown in Figure 4.

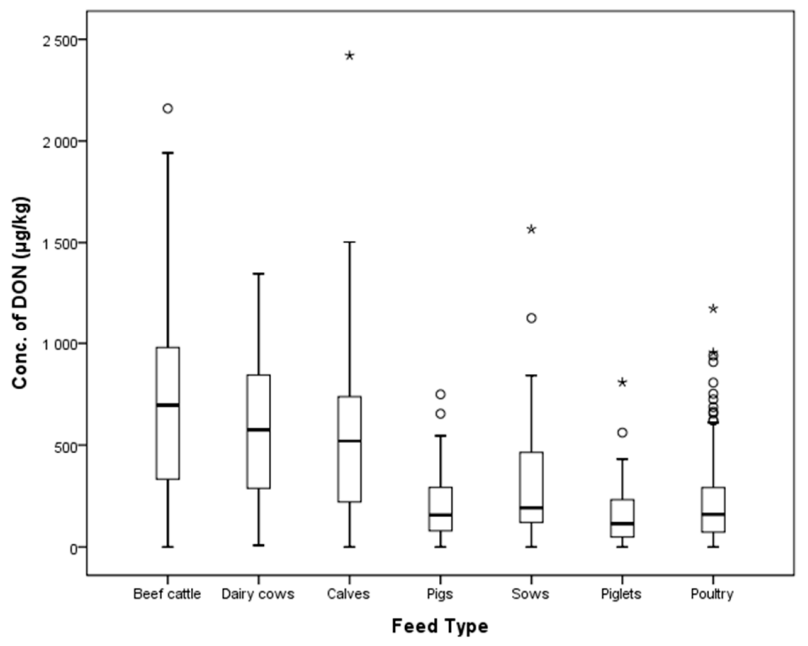

Figure 4. Distribution of DON in compound feeds (box-plot: whiskers at minimum and maximum, box at P25 and P75 with the line at P50; ${ }^{\circ}$ values above the 75 th percentile plus 1.5 times the inter-quartile distance; * values above the 75 th percentile plus 3.0 times the inter-quartile distance).

A total of 494 compound feeds (128, 90, 150, 60, and 66 compound feeds from 2009, 2010, 2012, 2014 , and 2016, respectively) were collected to analyze DON contamination levels (Figure 5). The mean contamination levels in each year were 426.8 (2009), 562.3 (2010), 314.5 (2012), 314.5 (2014), and $207.8 \mu \mathrm{g} / \mathrm{kg}$ (2016). The highest mean contamination level was found in $2010(p<0.001)$. There was a statistically-significant difference in mean contamination level for compound feeds collected in 2009, 2010, 2012, 2014, and 2016 in a one-way ANOVA ( $p<0.001$, Table 5), which revealed a generally decreasing trend without the contamination value in 2010. The occurrence of DON in selected years is shown in Figure 5.

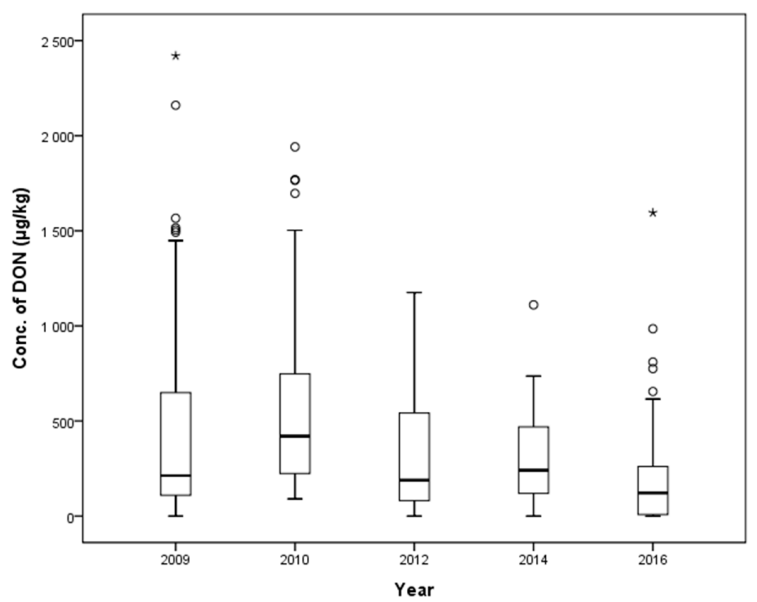

Figure 5. Distribution of DON in compound feed between 2009 and 2016 (box-plot: whiskers at minimum and maximum, box at P25 and P75 with the line at P50; ${ }^{\circ}$ values above the 75 th percentile plus 1.5 times the inter-quartile distance; ${ }^{*}$ values above the 75 th percentile plus 3.0 times the inter-quartile distance). 
Table 5. The mean values of DON concentration and differences in compound feeds across the years.

\begin{tabular}{ccccccc}
\hline \multirow{2}{*}{ Mycotoxin } & Year & \multicolumn{2}{c}{ Conc. of Mycotoxin $(\mu \mathrm{g} / \mathbf{k g})$} & \multirow{2}{*}{$\boldsymbol{F}$} & $\boldsymbol{p}$ \\
\cline { 3 - 4 } & & Mean & SD & & \\
\hline \multirow{3}{*}{ Deoxynivalenol } & 2009 & $426.76^{\mathrm{b}, \mathrm{c}}$ & 465.27 & & \\
& 2010 & $562.34^{\mathrm{c}}$ & 432.66 & & \\
& 2012 & $314.49^{\mathrm{a}, \mathrm{b}}$ & 292.86 & \multirow{2}{*}{$11.434^{* * *}$} & 0.000 \\
& 2014 & $314.5^{\mathrm{a}, \mathrm{b}}$ & 230.09 & & \\
\hline
\end{tabular}

${ }^{c}>{ }^{b},{ }^{b}>^{a}=$ significant mean difference by Scheffe tests, ${ }^{* * *} p<0.001 ; F, F$-value.

\subsection{Occurrence of DON in Feed Ingredients between 2009 and 2016}

Feed ingredient samples (159 samples) were gathered at five time points: first in 2009 and then every other year from 2010 to 2016 (2010, 2012, 2014 and 2016). The samples consisted of 22 grains, 36 grain by-products including brans, 76 meals including vegetable proteins, 8 fibrous feeds, 13 food by-products, and 4 other feed ingredients including beans, seed nuts, and mixed formulation. Detailed data related to the DON contamination level in tested feed ingredient samples are summarized in Table 6.

Table 6. DON concentrations in feed ingredients.

\begin{tabular}{|c|c|c|c|c|c|}
\hline Class & Feed Groups & $N^{(\mathrm{a})}$ & LC (\%) ${ }^{(b)}$ & Mean $(\mu \mathrm{g} / \mathrm{kg})$ & $\mathrm{SD}(\mu \mathrm{g} / \mathrm{kg})$ \\
\hline \multirow{2}{*}{ Grains } & Grains & 12 & 16.7 & 115.9 & 107.0 \\
\hline & Grain products & 10 & 40.0 & 74.2 & 102.2 \\
\hline \multirow{7}{*}{ Grain byproducts (brans) } & Corn gluten feed & 16 & 0 & 3603.7 & 2268.2 \\
\hline & Soybean hull & 6 & 33.3 & 600.1 & 1252.9 \\
\hline & Wheat shorts & 2 & 50.0 & 81.0 & 81.0 \\
\hline & Cotton seeds hull & 2 & 100.0 & 0.0 & 0.0 \\
\hline & Wheat bran & 3 & 66.7 & 180.4 & 255.2 \\
\hline & Corn bran & 5 & 0 & 511.4 & 174.8 \\
\hline & Other grain byproducts & 2 & 50.0 & 75.4 & 75.4 \\
\hline \multirow{7}{*}{ Meal } & Soybean meal & 16 & 50.0 & 27.1 & 32.3 \\
\hline & Corn gluten meal & 22 & 18.2 & 134.8 & 261.7 \\
\hline & Corn germ meal & 12 & 16.7 & 182.4 & 198.3 \\
\hline & Distillers dried grains & 14 & 21.4 & 908.1 & 850.7 \\
\hline & Coffee meal & 1 & 100.0 & 0.0 & 0.0 \\
\hline & Palm oil meal & 7 & 100.0 & 0.0 & 0.0 \\
\hline & Other meal & 4 & 100.0 & 0.0 & 0.0 \\
\hline Fibrous feed & Fibrous feed & 8 & 62.5 & 361.4 & 918.2 \\
\hline Food byproducts & Food byproducts & 13 & 38.5 & 22.4 & 19.2 \\
\hline Beans & Beans & 1 & 100.0 & 0.0 & 0.0 \\
\hline Seeds nuts & Seeds nuts & 2 & 100.0 & 0.0 & 0.0 \\
\hline Mixed formulation & Mixed formulation & 1 & 100.0 & 0.0 & 0.0 \\
\hline
\end{tabular}

${ }^{(a)} N$, number of samples; ${ }^{(b)}$ LC, percentage of left censored results (the percentage of data below the LOD) [23]

The contamination rates with DON in feed ingredient samples were $72.7,77.8,61.8,37.5$ and $61.5 \%$ in grains, grain by-products, meals, fibrous feed, and food by-products, respectively. Over half of the collected feed ingredient samples $(64 \%)$ showed contamination with DON. The average contamination level for DON was $555.3 \mu \mathrm{g} / \mathrm{kg}$ in the range of 0.01 to $8480.0 \mu \mathrm{g} / \mathrm{kg}$. This mycotoxin was detected in grains, grain by-products, meals, fibrous feed, and food by-products at concentrations of 96.9, $1796.4,240.8,361.4$ and $22.4 \mu \mathrm{g} / \mathrm{kg}$, respectively. DON was not found in beans, seed nuts, or mixed formulation. The distribution of DON in feeds is shown in Figure 6. 
According to the guidance values of the EC and South Korea for DON management (Table 1), DON in grains should be controlled at 8000 and $10,000 \mu \mathrm{g} / \mathrm{kg}$, respectively. In this study, no samples exceeded these values. While the highest DON level $(8480.0 \mu \mathrm{g} / \mathrm{kg})$ was detected in corn bran, this did not exceed the EC guidance value for maize by-products $(12,000 \mu \mathrm{g} / \mathrm{kg})$.

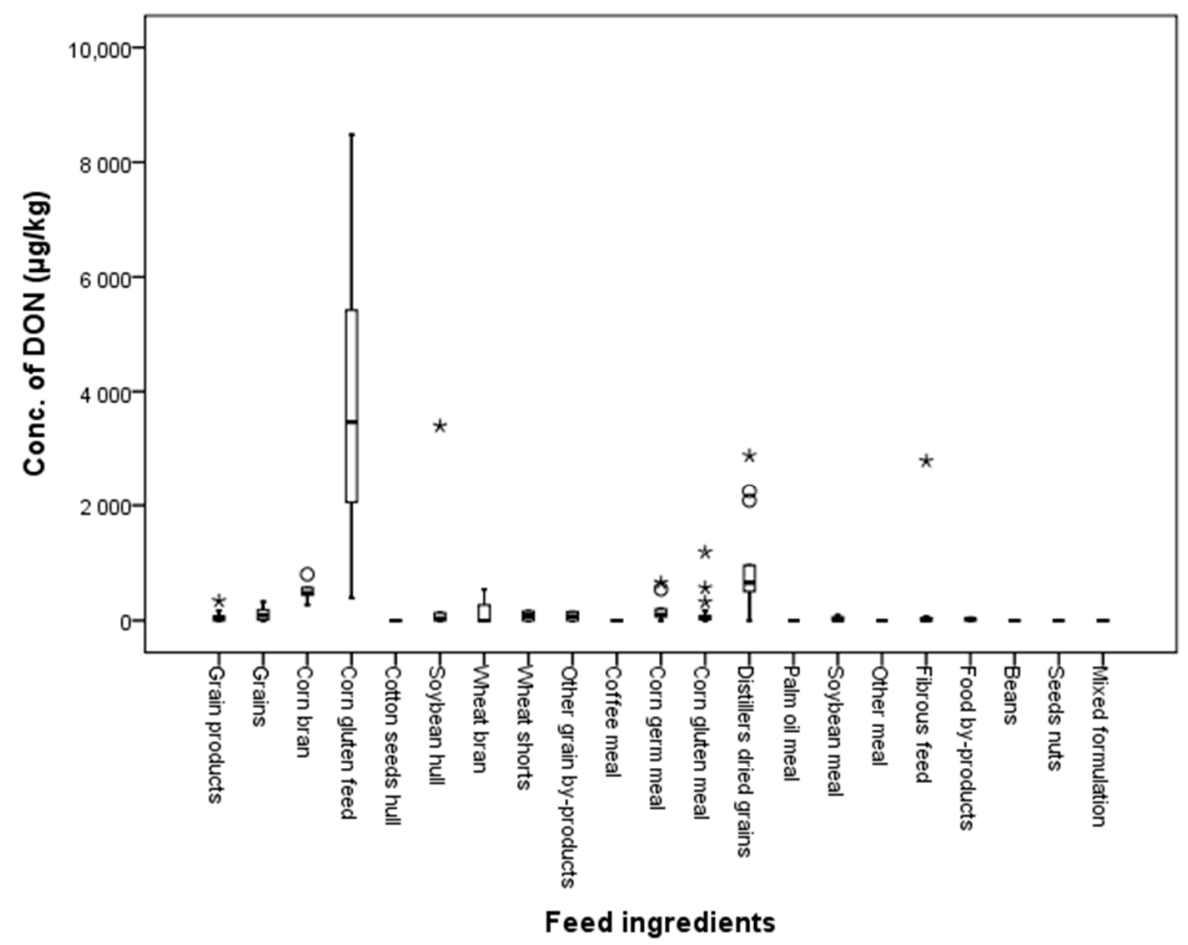

Figure 6. Distribution of DON in feed ingredients (box-plot: whiskers at minimum and maximum, box at P25 and P75 with the line at P50; ${ }^{\circ}$ values above the 75 th percentile plus 1.5 times the inter-quartile distance; ${ }^{*}$ values above the 75 th percentile plus 3.0 times the inter-quartile distance).

A total of 159 feed ingredient samples were collected during the time points: 2009 (66), 2010 (23), 2012 (30), 2014 (17), and 2016 (23), and the mean contamination levels were 756.5, 1159.8, 231.8, 42.5, and $174.2 \mu \mathrm{g} / \mathrm{kg}$, respectively. The highest mean contamination level was found in $2010(p<0.05)$. There was a statistically significant difference in mean contamination level for feed ingredients collected in 2009, 2010, 2012, 2014, and 2016 in a one-way ANOVA ( $p<0.05$, Table 7), which revealed a decreasing trend. The occurrence of DON in selected years is shown in Figure 7.

Table 7. The mean DON concentration and differences in feed ingredients across years.

\begin{tabular}{lcccccc}
\hline \multirow{2}{*}{ Mycotoxin } & Year & \multicolumn{2}{c}{ Conc. of Mycotoxin $(\mu \mathrm{g} / \mathbf{k g})$} & \multirow{2}{*}{$\boldsymbol{F}$} & $\boldsymbol{p}$ \\
\cline { 3 - 4 } & & Mean & SD & & \\
\hline \multirow{3}{*}{ Deoxynivalenol } & 2009 & 756.51 & 1735.03 & & \\
& 2010 & 1159.80 & 1636.07 & & \\
& 2012 & 231.77 & 289.41 & & \\
& 2014 & 42.49 & 110.32 & & \\
& 2016 & 174.19 & 602.91 & & \\
\hline \multicolumn{5}{c}{$*<0.05 ; F, F$-value. }
\end{tabular}




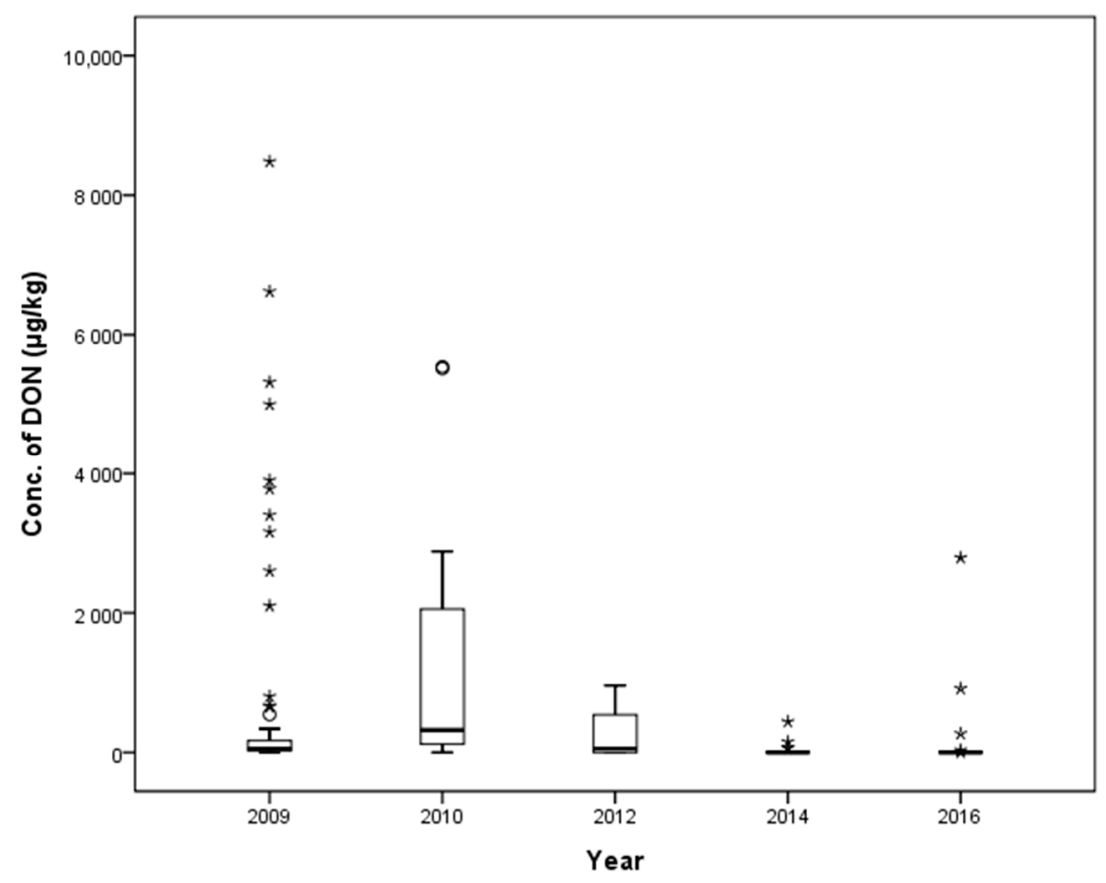

Figure 7. Distribution of DON in feed ingredients between 2009 and 2016 (box-plot: whiskers at minimum and maximum, box at P25 and P75 with the line at P50; ${ }^{\circ}$ values above the 75 th percentile plus 1.5 times the inter-quartile distance; ${ }^{*}$ values above the 75 th percentile plus 3.0 times the interquartile distance).

\section{Discussion}

The contamination of compound feeds by DON has been investigated in many countries. In Poland, DON was detected in $93.5 \%$ of 217 compound feed samples that were collected from 2006 to 2009 [24]. The average DON contamination level ranged from 136 to $225 \mu \mathrm{g} / \mathrm{kg}$ and with maximum contamination concentrations in the range of 409 to $2739 \mu \mathrm{g} / \mathrm{kg}$. In South Africa, a total of 92 commercial compound feed samples were collected and $70.3 \%$ of the collected samples were contaminated with DON [25]. The mean DON contamination was $766.6 \mu \mathrm{g} / \mathrm{kg}$, and the maximum value was $2352 \mu \mathrm{g} / \mathrm{kg}$. Two swine feed samples exceeded the DON contamination limit level for South Africa $(1000 \mu \mathrm{g} / \mathrm{kg})$. In Kuwait, DON was found in $88.8 \%$ of poultry feed samples [26]. The mean DON concentration in poultry feeds was estimated at $261.1 \mu \mathrm{g} / \mathrm{kg}$, within the range of 220 to $1200 \mu \mathrm{g} / \mathrm{kg}$. In that study, the concentration of DON was found to be lower than EC-recommended levels. In Turkey, DON was detected in $48.3 \%$ of entire feed samples that ranged from 18.5 to $500 \mu \mathrm{g} / \mathrm{kg}$ [27]. The mean DON contamination level was analyzed as $59.8 \mu \mathrm{g} / \mathrm{kg}$, and no sample exceeded the allowed level for DON in Turkey ( $5000 \mu \mathrm{g} / \mathrm{kg}$ for adult ruminants feed and $2000 \mu \mathrm{g} / \mathrm{kg}$ for lamb-calf feed). Another group reported a similar study that was conducted to determine DON levels in feed and feedstuff samples in Turkey [28]. A total of 106 samples were collected from several farms and feedstuffs manufacturers in Turkey. DON occurred in $18.4 \%$ of feedstuffs and $43.3 \%$ of feed samples. The highest determination level was $4769.6 \mu \mathrm{g} / \mathrm{kg}$ in maize gluten, indicating that DON content in feed and feedstuffs did not exceed the permitted levels. In 2016, Wu et al. [29] monitored the DON contamination in feed (2013-2015) obtained from several provinces in China. In that study, a total of 127 samples were analyzed using HPLC, and the highest detection level was at $3346.0 \mu \mathrm{g} / \mathrm{kg}$ in pig feed (pellet) in 2015, which exceeded the guidance values in pig complete feed in China $(1000 \mu \mathrm{g} / \mathrm{kg})$.

In this study, DON contamination was measured in 494 compound feed samples comprising 174 cattle feeds, 160 pig feeds, and 160 poultry feeds that were collected in 2009 and then every two years from 2010, 2012, 2014 and 2016. DON was detected in 95.3\% of all of the compound feed samples with a range of 0.4 to $2420.0 \mu \mathrm{g} / \mathrm{kg}$. DON was analyzed in $97.7 \%$ of cattle feeds, $93.1 \%$ of pig feeds, 
and $95.0 \%$ of poultry feeds. In the case of cattle and poultry feeds, the maximum contamination level was $2420.0 \mu \mathrm{g} / \mathrm{kg}$ and $1175.2 \mu \mathrm{g} / \mathrm{kg}$, respectively. No sample exceeded the EU commission levels (5000 $\mu \mathrm{g} / \mathrm{kg}$ for other feeds except calf and pig feeds). However, among pig feeds, two compound feeds including gestating sow feeds in $2009(1566.0 \mu \mathrm{g} / \mathrm{kg})$ and $2010(1128.8 \mu \mathrm{g} / \mathrm{kg})$ exceeded the EC guidance value $(900 \mu \mathrm{g} / \mathrm{kg}$ for pig feeds).

Research related to DON contamination levels in feed ingredients has been performed in many countries. In Thailand, Poapolathep et al. monitored 90 wheat and wheat product samples [30] and showed that $18.9 \%$ of total samples were contaminated with DON in the range of 130 to $1130 \mu \mathrm{g} / \mathrm{kg}$ with a mean contamination level of $280.6 \mu \mathrm{g} / \mathrm{kg}$, suggesting that the risk of DON exposure from wheat products is very low. In China, 83 feed ingredients samples were analyzed, and $95.2 \%$ of total samples were contaminated with DON with an average concentration of $1670.2 \mu \mathrm{g} / \mathrm{kg}$ [31]. The maximum contamination level of DON was $13,139.4 \mu \mathrm{g} / \mathrm{kg}$, which exceeded the EC guidance value $(8000 \mu \mathrm{g} / \mathrm{kg})$. In the Netherlands, 140 maize silage samples and 20 wheat silage samples were collected, and DON was detected in $72 \%$ and $10 \%$ of the samples, respectively [32]. Average concentration levels of DON were 854 and $621 \mu \mathrm{g} / \mathrm{kg}$, respectively, and maximum concentration levels were 3142 and $1165 \mu \mathrm{g} / \mathrm{kg}$, respectively, and no samples exceeded the guidance value for DON (8000 $\mu \mathrm{g} / \mathrm{kg})$. In Tunisia, 83\% of entire durum wheat samples were contaminated with DON [16], with an average concentration of DON that ranged from $12,800 \pm 5 \%$ to $13,300 \pm 13.3 \% \mu \mathrm{g} / \mathrm{kg}$, which exceeded the EC guidance value for wheat $(1750 \mu \mathrm{g} / \mathrm{kg})$. In Serbia, a total of 289 feed ingredient samples were collected from 2004 to 2007 [33]. Some samples (33.2\%) were contaminated with DON, and the average concentration of DON was $253 \mu \mathrm{g} / \mathrm{kg}$. Three samples (two maize samples and a wheat sample) exceeded the guidance value. Wu et al. [29] estimated the level of contamination for DON in a total of 443 feed ingredient samples collected in China. Almost all samples were contaminated with DON (83.3\% to 100\%), and soybean meal showed the lowest incidence of DON (66.7\%). Interestingly, in Hungary, wheat (305) and maize (108) were analyzed to estimate DON contamination levels collected from 2008 to 2015 [34]. In wheat samples, the highest mean contamination level of $2159 \mu \mathrm{g} / \mathrm{mL}$ and the lowest mean level of $181 \mu \mathrm{g} / \mathrm{mL}$ were observed in 2011 and 2012, respectively. However, in maize, the highest mean value $(1261 \mu \mathrm{g} / \mathrm{mL})$ and the lowest mean value $(73 \mu \mathrm{g} / \mathrm{mL})$ were observed in 2014 and 2009, respectively.

In this study, over half of the collected feed ingredient samples (64\%) were found to be contaminated in South Korea. The average DON contamination concentration was $555.3 \mu \mathrm{g} / \mathrm{kg}$ with a range of 0.01 to $8480.0 \mu \mathrm{g} / \mathrm{kg}$. DON was detected at a concentration of $96.9,1796.4,240.8$, 361.4 , and $22.4 \mu \mathrm{g} / \mathrm{kg}$ in grains, grain by-products, meals, fibrous feed, and food by-products, respectively. No samples exceeded the guidance values for the EU or South Korea (8000 and $1000 \mu \mathrm{g} / \mathrm{kg}$, respectively). In the case of corn bran, a maximum of $8480.0 \mu \mathrm{g} / \mathrm{kg}$ of DON was detected, but this did not exceed the EC guidance value for corn bran $(12,000 \mu \mathrm{g} / \mathrm{kg})$.

There was a significant difference in the mean contamination level of DON in compound feed and feed ingredients over time in Korea that indicated a decreasing trend. This is mainly due to the continuous monitoring of Fusarium mycotoxins in feeds for many years and to the designation of guidance values for Fusarium mycotoxins since 2015.

\section{Materials and Methods}

\subsection{Chemicals and Reagents}

The standard reagent for DON analysis was purchased from Sigma Chemical Co. (St. Louis, MO, USA). Phosphate-buffered saline (PBS) was also obtained from Sigma-Aldrich for elution of DON in immunoaffinity column chromatography. Acetonitrile and methanol used in DON extraction were products of Honeywell Burdick \& Jackson (Morris Plains, NJ, USA). The DONPREP kit (R-Biopharm ${ }^{\circledR}$, Darmstadt, Germany) and DON Test kit (Vicam ${ }^{\circledR}$, Palo Alto, CA, USA) were used for DON purification. The DON standard reagent was dissolved in acetonitrile to prepare standard solutions of high 
concentration, which were then diluted with $20 \%$ acetonitrile for use in analysis (acetonitrile: distilled water $=20: 80, v: v)$.

\subsection{Sampling of Feeds and Feed Ingredients}

Contamination levels of DON were analyzed in 653 different feed samples (494 compound feed samples and 159 feed ingredients) produced in 2009 and every other year from 2010 to 2016. These samples were gathered at livestock feed factories from South Korea according to the annual procedure of the Ministry of Agriculture, Food, and Rural Affairs. The descriptions of compound feed and feed ingredient samples are shown in Tables 8 and 9. All the samples were preprocessed according to the general guidelines on sampling from the FAO and WHO [35]. Random sample collection included choosing one kilogram per every ton of feed samples. Samples were collected four times from the same group, and the mixed sample was divided into another four groups. All of the divided samples were subdivided into $200 \mathrm{~g}$ and stored in a refrigerator at $4{ }^{\circ} \mathrm{C}$. Detailed classification data for compound feed and feed ingredient samples are shown in the supplementary data (Tables S1-S5).

Table 8. Compound feed samples between 2009 and 2016.

\begin{tabular}{|c|c|c|c|c|c|c|c|}
\hline \multirow{2}{*}{ Livestock } & \multirow{2}{*}{ Feed Type } & \multicolumn{6}{|c|}{ No. of Samples } \\
\hline & & Total & 2009 & 2010 & 2012 & 2014 & 2016 \\
\hline \multirow{5}{*}{ Beef cattle } & Early beef cattle & 21 & 9 & 2 & 6 & 2 & 2 \\
\hline & Middle beef cattle & 8 & - & 3 & - & 2 & 3 \\
\hline & Late beef cattle & 20 & 7 & 4 & 6 & 1 & 2 \\
\hline & Gestating beef cattle & 29 & 13 & 7 & 5 & 2 & 2 \\
\hline & Lactating beef cattle & 2 & - & - & - & - & 2 \\
\hline \multirow{5}{*}{ Dairy cows } & Dairy cows in early lactation & 16 & 6 & 2 & 6 & 1 & 1 \\
\hline & Dairy cows in mid lactation & 5 & 2 & 2 & - & 1 & - \\
\hline & Dairy cows on dry & 4 & 1 & - & - & 2 & 1 \\
\hline & High yielding dairy cows & 9 & 1 & - & 5 & 2 & 1 \\
\hline & Gestating dairy cows & 5 & - & 3 & - & 1 & 1 \\
\hline \multirow{7}{*}{ Calves } & Early beef calves & 9 & - & - & 5 & 1 & 3 \\
\hline & Middle beef calves & 11 & 1 & - & 6 & 1 & 3 \\
\hline & Early dairy calves & 1 & - & - & - & - & 1 \\
\hline & Middle dairy calves & 15 & 4 & 3 & 6 & 1 & 1 \\
\hline & Late dairy calves & 13 & 3 & 4 & 5 & 1 & - \\
\hline & Middle breeding calves & 1 & - & - & - & - & 1 \\
\hline & Late breeding calves & 5 & 1 & - & - & 2 & 2 \\
\hline \multirow{2}{*}{ Pigs } & Early growing pigs & 30 & 12 & 5 & 10 & 3 & - \\
\hline & Late growing pigs & 18 & 4 & 5 & 5 & 4 & - \\
\hline \multirow{3}{*}{ Sows } & Gestating sows & 32 & 6 & 10 & 10 & 3 & 3 \\
\hline & Lactating sows & 25 & 5 & 5 & 10 & 3 & 2 \\
\hline & Breeding gilts & 1 & - & - & - & 1 & - \\
\hline \multirow{2}{*}{ Piglets } & Sucking piglets & 8 & - & - & 5 & 2 & 1 \\
\hline & Weanling piglets & 46 & 13 & 5 & 10 & 4 & 14 \\
\hline \multirow{11}{*}{ Poultry } & Early layer chicks & 9 & 3 & 3 & - & 1 & 2 \\
\hline & Middle layer chicks & 22 & 4 & 7 & 6 & 3 & 2 \\
\hline & Late layer chicks & 8 & - & - & 5 & 3 & - \\
\hline & Early laying hens & 27 & 5 & 6 & 10 & 3 & 3 \\
\hline & Middle laying hens & 11 & - & - & 5 & 3 & 3 \\
\hline & Late laying hens & 2 & - & - & - & - & 2 \\
\hline & Early broilers & 37 & 12 & 7 & 10 & 4 & 4 \\
\hline & Late broilers & 33 & 12 & 7 & 9 & 3 & 2 \\
\hline & Finishing broilers & 2 & - & - & - & - & 2 \\
\hline & Breeding broilers & 9 & 4 & - & 5 & - & - \\
\hline & Total & 494 & 128 & 90 & 150 & 60 & 66 \\
\hline
\end{tabular}


Table 9. Feed ingredient samples between 2009 and 2016.

\begin{tabular}{|c|c|c|c|c|c|c|c|}
\hline \multirow{2}{*}{ Class } & \multirow{2}{*}{ Feed Type } & \multicolumn{6}{|c|}{ No. of Samples } \\
\hline & & Total & 2009 & 2010 & 2012 & 2014 & 2016 \\
\hline \multirow{2}{*}{ Grain } & Grain & 12 & 7 & 4 & - & - & 1 \\
\hline & Grain products & 10 & 7 & - & 2 & - & 1 \\
\hline \multirow{7}{*}{ Grain-by products (bran) } & Corn gluten feed & 16 & 9 & 5 & 2 & - & - \\
\hline & Soybean hull & 6 & 5 & - & - & 1 & - \\
\hline & Wheat shorts & 2 & - & - & 1 & 1 & - \\
\hline & Cotton seeds hull & 2 & - & - & 1 & 1 & - \\
\hline & Wheat bran & 3 & - & - & 2 & 1 & - \\
\hline & Corn bran & 5 & 1 & - & 2 & 1 & 1 \\
\hline & Other grain by-products & 2 & - & - & - & 1 & 1 \\
\hline \multirow{7}{*}{ Meal (vegetable proteins) } & Soybean meal & 16 & 10 & - & 2 & 3 & 1 \\
\hline & Corn gluten meal & 22 & 10 & 5 & 4 & 3 & - \\
\hline & Corn germ meal & 12 & 4 & 4 & 2 & 1 & 1 \\
\hline & Distillers dried grains & 14 & 2 & 5 & 6 & - & 1 \\
\hline & Coffee meal & 1 & - & - & 1 & - & - \\
\hline & Palm oil meal & 7 & 4 & - & 3 & - & - \\
\hline & Other meal & 4 & - & - & - & 1 & 3 \\
\hline Fibrous feed & Fibrous feed & 8 & - & - & - & 2 & 6 \\
\hline Food by-products & Food by-products & 13 & 7 & - & 2 & 1 & 3 \\
\hline Beans & Beans & 1 & - & - & - & - & 1 \\
\hline Seeds nuts & Seeds nuts & 2 & - & - & - & - & 2 \\
\hline Mixed formulation & Mixed formulation & 1 & - & - & - & - & 1 \\
\hline \multicolumn{2}{|c|}{ Total } & 159 & 66 & 23 & 30 & 17 & 23 \\
\hline
\end{tabular}

\subsection{Extraction and Purification}

The animal feed samples were ground to a particle size of $600 \mu \mathrm{m}$ using a homogenizer, and $20 \mathrm{~g}$ of each feed was used as an analytical sample. The feed samples were mixed with distilled water $(120 \mathrm{~mL})$, and the mixture was extracted with a homogenizer at $7000 \mathrm{rpm}$ for $2 \mathrm{~min}$. After filtration of the extract through Whatman No. 4 filter paper (GE Healthcare Life Science, Maidstone, Kent, UK), $3 \mathrm{~mL}$ of the filtrate was added to an IAC prepared previously in a Vac Elut 20 Manifold (Agilent Technologies, Santa Clara, CA, USA). For an adequate reaction between the IAC packing material and $\mathrm{DON}$, the flow rate was adjusted to 2 to $3 \mathrm{~mL}$ per minute. The extracts were passed through the IAC, and, after washing with $5 \mathrm{~mL}$ of distilled water, the distilled water was removed using a vacuum pump. The mycotoxin attached to the IAC was eluted with $3 \mathrm{~mL}$ methanol, which was slowly dropped under gravity. To increase the elution efficiency, back flushing was performed three times using a syringe before methanol was completely eluted from the IAC. The eluted solution was completely dried at $50{ }^{\circ} \mathrm{C}$ using a nitrogen micro-concentrator and re-dissolved in $20 \%$ acetonitrile. The re-dissolved solution was filtered through a syringe filter $(0.22 \mu \mathrm{m}$ pore size $)$ and used as a solution for analyzing.

\subsection{HPLC Analysis of DON}

The concentration of DON in compound feed and feed ingredient samples was measured using HPLC. In analysis, Agilent 1100 series (Santa Clara, CA, USA) including a degasser, auto sampler, a ZORBAX Eclipse XDB-C18 column $(4.6 \times 250 \mathrm{~mm}, 5 \mu \mathrm{m})$, and a guard column C18 $(4.6 \times 10 \mathrm{~mm}, 5 \mu \mathrm{m})$ were used at $30{ }^{\circ} \mathrm{C}$. DON was separated using HPLC for $20 \mathrm{~min}$ at a flow rate of $1 \mathrm{~mL} / \mathrm{min}$ and detected with a diode array detector at $220 \mathrm{~nm}$. The mobile phase was composed of HPLC grade water and acetonitrile, which was used in the gradient mode. The retention time was $4.4 \mathrm{~min}$ after injection of $20-\mu \mathrm{L}$ samples.

\subsection{Method Validation}

The method of HPLC analysis for DON detection was verified by evaluating linearity, LOD, LOQ, accuracy, and precision. All parameters were calculated according to the ICH guidelines [36]. To determine 
linearity, the standard curve range was between 50 and $1000 \mu \mathrm{g} / \mathrm{kg}(50,100,200,250,500$, and $1000 \mu \mathrm{g} / \mathrm{kg})$, and the regression equation was calculated using the peak area and concentration of standard solution as parameters. The regression coefficient $\left(R^{2}\right)$ was used to confirm the linearity. The LOD and LOQ were calculated, which were the signal to noise ratio of 3 and 10. To determine accuracy, the recovery test included spiking a blank sample with various concentrations of DON standards, and the results are expressed as the recovery ratio. In this study, the precision indicated the degree of repeatability, and the percent relative standard deviation (\%RSD) was used to calculate precision.

Supplementary Materials: The following are available online at http:/ /www.mdpi.com/2072-6651/10/3/127/s1. Table S1: Description of compound feeds for cattle. Table S2: Description of compound feeds for swine. Table S3: Description of compound feeds for poultry. Table S4: Description of compound feeds for dairy cows. Table S5: Description of feed ingredients.

Acknowledgments: This research was supported by the Chung-Ang University Graduate Research Scholarship in 2017.

Author Contributions: C.L. conceived and designed the experiments. J.P. and H.C. performed the experiments. S.C. and D.K. analyzed the data. C.L. wrote the paper.

Conflicts of Interest: The authors have no conflicts of interest to declare.

\section{References}

1. Pestka, J.J. Deoxynivalenol: Mechanisms of action, human exposure, and toxicological relevance. Arch. Toxicol. 2010, 84, 663-679. [CrossRef] [PubMed]

2. Therholm, H.L.; Cochrane, W.P.; Cohen, H.; Elliot, J.I.; Farnworth, E.R.; Friend, D.W.; Hamilton, R.M.G.; Standish, J.F.; Thompson, B.K. Survey of vomitoxin contamination of 1980 Ontario (Canada) white winter wheat crop: Results of survey and feeding trials. J. Assoc. Off. Anal. Chem. 1983, 66, 92-97.

3. Müller, H.M.; Schwadorf, K. A survey of the natural occurrence of Fusarium toxins in wheat grown in a southwestern area of Germany. Mycopathologia 1993, 121, 115-121. [CrossRef]

4. Chulze, S.N.; Ramirez, M.L.; Farnochi, M.C.; Pascale, M.; Visconti, A.; March, G. Fusarium and Fumonisin occurrence in Argentinian corn at different ear maturity stages. J. Agric. Food Chem. 1996, 44, 2797-2801. [CrossRef]

5. Viquez, O.M.; Castell-Perez, M.E.; Shelby, R.A. Occurrence of Fumonisin $B_{1}$ in maize grown in Costa Rica. J. Agric. Food Chem. 1996, 44, 2789-2791. [CrossRef]

6. Bennett, J.W.; Klich, M. Mycotoxins. Clin. Microbiol. Rev. 2003, 16, 497-516. [CrossRef] [PubMed]

7. Ueno, Y. Toxicological features of T-2 toxin related trichothecenes. Appl. Toxicol. 1984, 4, 124-132. [CrossRef]

8. Yoshizawa, T.; Morooka, N. Deoxynivalenol and its monoacetate: New mycotoxins from Fusaruium roseum and moldy barley. Agric. Biol. Chem. 1973, 37, 2933-2934. [CrossRef]

9. European Food Safety Authority (EFSA). Opinion of the scientific panel on contaminants in the food chain on a request from the commission related to deoxynivalenol (DON) as undesirable substance in animal feed. EFSA J. 2004, 73, 1-41.

10. Ueno, Y.; Sato, N.; Ishii, K.; Sakai, K.; Tsunoda, H.; Enomoto, M. Biological and chemical detection of trichothecene mycotoxins of Fusarium species. Appl. Toxicol. 1973, 25, 699-704.

11. Girish, C.K.; MacDonald, E.J.; Scheinin, M.; Smith, T.K. Effects of Feedborne Fusarium Mycotoxins on Brain Regional Neurochemistry of Turkeys. Poult. Sci. 2008, 87, 1295-1302. [CrossRef] [PubMed]

12. Accensi, F.; Pinton, P.; Callu, P.; Abella-Bourges, N.; Guelfi, J.F.; Grosjean, F.; Oswald, P. Ingestionof low doses of deoxynivalenol does not affect hematological, biochemical, orimmune responses of piglets. J. Anim. Sci. 2006, 84, 1935-1942. [CrossRef] [PubMed]

13. Bryden, W.L. Mycotoxin contamination of the feed supply chain: Implications for animal productivity and feed security. Anim. Feed Sci. Technol. 2012, 173, 134-158. [CrossRef]

14. Rodrigues, I.; Naehrer, K. A Three-Year Survey on the Worldwide Occurrence of Mycotoxins in Feedstuffs and Feed. Toxins 2012, 4, 663-675. [CrossRef] [PubMed]

15. Cui, L.; Selvaraj, J.M.; Xing, F.; Zhao, Y.; Zhou, L.; Liu, Y. A minor survey of deoxynivalenol in Fusarium infected wheat from Yangtze-Huaihe river basin region in China. Food Control 2013, 30, 469-473. [CrossRef]

16. Bensassi, F.; Zaied, C.; Abid, S.; Hajlaoui, M.R.; Bacha, H. Occurrence of deoxynivalenol in durum wheat in Tunisia. Food Control 2010, 21, 281-285. [CrossRef] 
17. Pietsch, C.; Kersten, S.; Burkhardt-Holm, P.; Valenta, H.; Dänicke, S. Occurrence of Deoxynivalenol and Zearalenone in Commercial Fish Feed: An Initial Study. Toxins 2013, 5, 184-192. [CrossRef] [PubMed]

18. Kim, D.H.; Lee, I.H.; Do, W.H.; Nam, W.S.; Li, H.; Jang, H.S.; Lee, C. Incidence and levels of deoxynivalenol, fumonisins and zearalenone contaminants in animal feeds used in Korea in 2012. Toxins 2014, 6, $20-32$. [CrossRef] [PubMed]

19. European Commission (EC). COMMISSION RECOMMENDATION of 17 August 2006 on the presence of deoxynivalenol, zearalenone, ochratoxin A, T-2 and Ht-2 and fumonisins in products intended for animal feeding. Off. J. Eur. Union 2006, L229, 7-9.

20. National Law Information Center. Available online: http://www.law.go.kr/admRulSc.do? menuId=1\& query= $\%$ EC $\% 82 \% A C \% E B \% A 3 \% 8 C \% 20 \% E B \% 93 \% B 1 \% E C \% 9 D \% 98 \% 20 \% E A \% B 8 \% B 0 \% E C \% A 4 \% 80 \% 20 \%$ EB\%B0\%8F\%20\%EA\%B7\%9C\%EA\%B2\%A9\#liBgcolor0 (accessed on 5 December 2017).

21. Park, J.; Chang, H.; Hong, S.; Kim, D.; Chung, S.; Lee, C. A Decrease of Incidence Cases of Fumonisins in South Korean Feedstuff between 2011 and 2016. Toxins 2017, 9, 286. [CrossRef] [PubMed]

22. European Commission (EC). COMMISSION REGULATION (EC) No. 401/2006 of 23 February 2006 laying down the methods of sampling and analysis for the official control of the levels of mycotoxins in foodstuffs. Off. J. Eur. Union 2006, L70, 12-34.

23. European Food Safety Authority (EFSA). Management of left-consored data in dietary exposure assessment of chemical substances. EFSA J. 2010, 8, 1557-1653.

24. Grajewski, J.; Blajet-Kosicka, A.; Twaruzek, M.; Kosicki, R. Occurrence of mycotoxins in Polish animal feed in years 2006-2009. J. Anim. Physiol. Anim. Nutr. 2012, 96, 870-877. [CrossRef] [PubMed]

25. Njobeh, P.B.; Dutton, M.F.; Åberg, A.T.; Haggblom, P. Estimation of multi-mycotoxin contamination in South African compound feeds. Toxins 2012, 4, 836-848. [CrossRef] [PubMed]

26. Beg, M.U.; Al-Mutairi, M.; Beg, K.R.; Al-Mazeedi, H.M.; Ali, L.N.; Saeed, T. Mycotoxins in poultry feed in Kuwait. Arch. Environ. Contam. Toxicol. 2006, 50, 594-602. [CrossRef] [PubMed]

27. Kocasari, F.S.; Mor, F.; Oguz, M.N.; Oguz, F.K. Occurrence of mycotoxins in feed samples in Burdur province, Turkey. Environ. Monit. Assess. 2013, 185, 4943-4949. [CrossRef] [PubMed]

28. Bilal, T.; Aksakal, D.H.; Sünnetci, S.; Keser, O.; Eseceli, H. Detection of Aflatoxin, Zearalenone and Deoxynivalenol in Some Feed and Feedstuffs in Turkey. Pak. Vet. J. 2014, 34, 459-463.

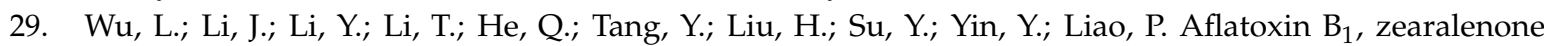
and deoxynivalenol in feed ingredients and complete feed from different Province in China. J. Anim. Sci. Biotechnol. 2016, 7, 63. [CrossRef] [PubMed]

30. Poapolathep, A.; Poapolathep, S.; Klangkaew, N.; Konishi, Y.S.; Kumagai, S. Detection of deoxynivalenol contamination in wheat products in Thailand. J. Food Prot. 2008, 71, 1931-1933. [CrossRef] [PubMed]

31. Guan, S.; Gong, M.; Yin, Y.; Huang, R.; Ruan, Z.; Zhou, T.; Xie, M. Occurrence of mycotoxins in feeds and feed ingredients in China. J. Food Agric. Environ. 2011, 9, 163-167.

32. Driehuis, F.; Spanjer, M.C.; Scholten, J.M.; Te Giffel, M.C. Occurrence of mycotoxins in maize, grass and wheat silage for dairy cattle in the Netherlands. Food Addit. Contam. Part B Surveill. 2008, 1, 41-50. [CrossRef] [PubMed]

33. Jajić, I.; Jurić, V.; Glamočič, D.; Abramovič, B. Occurrence of deoxynivalenol in maize and wheat in Serbia. Int. J. Mol. Sci. 2008, 9, 2114-2126. [CrossRef] [PubMed]

34. Tima, H.; Berkics, A.; Hannig, Z.; Ittzés, A.; Nagy, E.K.; Mohácsi-Farkas, C.; Kiskó, G. Deoxynivalenol in wheat, maize flour and pasta: Surveys in Hungary in 2008-2015. Food Addit. Contam. Part B Surveill. 2017, 11, 1-6. [CrossRef] [PubMed]

35. Food and Agriculture Organization (FAO)/World Health Organization (WHO). The Codex General Guidelines on Sampling-CAC/GL 50-2004; FAO: Rome, Italy; WHO: Geneva, Switzerland, 2004.

36. ICH Harmonization for Better Health. Available online: https:/ /www.ich.org/fileadmin/Public_Web_Site/ ICH_Products/Guidelines/Quality/Q2_R1/Step4/Q2_R1_Guideline.pdf (accessed on 1 December 2017).

(C) 2018 by the authors. Licensee MDPI, Basel, Switzerland. This article is an open access article distributed under the terms and conditions of the Creative Commons Attribution (CC BY) license (http:/ / creativecommons.org/licenses/by/4.0/). 